\title{
Caracterización molecular y evaluación del riesgo de Listeria monocytogenes en carne de vacuno y ave
}

\author{
Claudia Foerster ${ }^{1}$, Guillermo Figueroa \\ ${ }^{1}$ Laboratorio de Microbiología y Probióticos, INTA, Universidad de Chile. \\ Email: claudia.foerster@gmail.com
}

\begin{abstract}
Resumen
Listeria monocytogenes es un patógeno alimentario altamente letal que causa una enfermedad llamada listeriosis. El objetivo de este trabajo fue conocer aspectos epidemiológicos de este patógeno en carnes crudas listas para la venta. Se incluyeron 91 aislados de carne de ave y vacuno y se les comparó mediante electroforesis de campo pulsado (PFGE) con 3 cepas asociadas a casos de listeriosis humana en Chile. Se realizó además una evaluación probabilística del riesgo (EPR) de infectarse y/o enfermar por $L$. monocytogenes por el consumo de pollo y carne de vacuno. El modelo incluyó parámetros desde retail hasta el hogar y las distribuciones se compararon mediante un Análisis de Monte Carlo incluido en el Software @Risk.

Los resultados del PFGE, revelaron 2 relaciones de similitud $>90 \%$ entre subtipos de aislados de carne y listeriosis humana. Con la EPR se estimó un promedio de 228 (D.E=3.439) y 3 infectados (D.E=103) y 39 (D.E=552) y 1 enfermos (D.E=13) por consumo de carne de vacuno y pollo respectivamente. Las variables de mayor peso fueron la concentración de bacterias y la dosis infectante del 50\% de la población (ID50).

La carne cruda puede ser considerada como un alimento de riesgo para enfermar o infectarse con $L$. monocytogenes si no existe una cocción y/o manipulación adecuada. Por esto, la educación del consumidor es esencial para prevenir la listeriosis por consumo de estos productos. El generar mayor información nacional, sobre todo de concentración e ID50, debe ser prioridad para disminuir las incertidumbres de futuras evaluaciones de riesgo.
\end{abstract}

Finaciamiento: Beca Conicyt Doctorado en Chile y Apoyo de Tesis 